\title{
Real-time single-frequency precise point positioning: accuracy assessment
}

\author{
Roel J. P. van Bree • Christian C. J. M. Tiberius
}

Received: 6 July 2010/Accepted: 14 May 2011/Published online: 5 June 2011

(C) The Author(s) 2011. This article is published with open access at Springerlink.com

\begin{abstract}
The performance of real-time single-frequency precise point positioning is demonstrated in terms of position accuracy. This precise point positioning technique relies on predicted satellite orbits, predicted global ionospheric maps, and in particular on real-time satellite clock estimates. Results are presented using solely measurements from a user receiver on the L1-frequency ( $\mathrm{C} 1$ and L1), for almost 3 months of data. The empirical standard deviations of the position errors in North and East directions are about $0.15 \mathrm{~m}$, and in Up direction about $0.30 \mathrm{~m}$. The $95 \%$ errors are about $0.30 \mathrm{~m}$ in the horizontal directions, and $0.65 \mathrm{~m}$ in the vertical. In addition, single-frequency results of six receivers located around the world are presented. This research reveals the current ultimate real-time single-frequency positioning performance. To put these results into perspective, a case study is performed, using a moderately priced receiver with a simple patch antenna.
\end{abstract}

Keywords Single frequency - Precise point positioning Real-time satellite clocks - Real-time positioning results

$\begin{array}{ll}\text { Abbreviations } \\ \text { CODE } & \text { Center for Orbit Determination } \\ \text { DCB } & \text { Differential Code Bias } \\ \text { DLR } & \text { Deutsches Zentrum für Luft-und Raumfahrt/ } \\ & \text { German Aerospace Center } \\ \text { DOY } & \text { Day of year } \\ \text { GIM } & \text { Global Ionospheric Map } \\ \text { GSOC } & \text { German Space Operations Center }\end{array}$

R. J. P. van Bree $(\varangle) \cdot$ C. C. J. M. Tiberius

Delft University of Technology, Delft, The Netherlands

e-mail: R.J.P.vanBree@tudelft.nl

C. C. J. M. Tiberius

e-mail: C.C.J.M.Tiberius@tudelft.nl $\begin{array}{ll}\text { IGS } & \text { International GNSS Service } \\ \text { PRN } & \text { Pseudo Random Noise (code) } \\ \text { RETICLE } & \text { REal-TIme CLock Estimation } \\ \text { RT } & \text { Real-Time } \\ \text { SF-PPP } & \text { Single-frequency precise point positioning }\end{array}$

\section{Introduction}

The use of external satellite clock corrections cannot be avoided in precise point positioning (PPP), because, contrary to differential positioning, satellite clock offsets do not cancel in a standalone receiver setup. The most commonly used source for these satellite clock corrections is the International GNSS Service (IGS) (Dow et al. 2005) from which corrections are available with different latencies, ranging from $3 \mathrm{~h}$ for ultra rapid, to $17 \mathrm{~h}$ for rapid, and 13 days for final products. With the development of realtime applications of PPP, such as high-precision agriculture, navigation applications in the automotive and telecom markets, hydrography, and possibly even automated aircraft landing, a need rises for precise satellite clock corrections to be available in real time. Recently, real-time clock estimates with a latency of only a few seconds and an improved accuracy have become available through the Internet by several providers. In this research, satellite clock and orbit estimates are taken from the REal-TIme CLock Estimation (RETICLE) service, which has been developed at the German Space Operations Center of the German Aerospace Center (GSOC/DLR).

In van Bree et al. (2009), the performance of these new real-time clock and orbit products was analyzed. In the present research, we focus on the resulting position accuracy. In addition, another large error source in PPP is 
addressed, namely the pseudorange code observation noise of the receiver. The main part of the research consists of positioning performance analysis of high-end low-noise receivers, followed by a case study using a less costly receiver with a simple antenna.

For the main analysis, a high-end receiver with low code noise figures is used to demonstrate the ultimate performance of real-time single-frequency precise point positioning (RT SF-PPP). With a dataset spanning 83 consecutive days, the performance is analyzed at L1 frequency with this receiver located in Delft. Next, data of six receivers from the IGS network at several locations around the world are analyzed, also to demonstrate ionospheric map coverage and RETICLE satellite clock and satellite orbit quality. In a separate case study, a moderately priced receiver is used, with a simple patch antenna, in order to put the performance of the high-end receiver into perspective.

\section{Single-frequency PPP}

At present, SF-PPP is already used in the GNSS community. A detailed description of SF-PPP can be found in Héroux and Kouba (1995), Øvstedal (2002), Gao, Zhang and Chen (2006), and Le and Tiberius (2007). The best position accuracy with SF-PPP is reached when precise GPS data products are used, i.e., final satellite clocks and orbits, final ionospheric maps, and the latest differential code biases (DCB). These products, however, are available to the user with a significant latency of a few days or even weeks after the measurement epoch. When a real-time position solution is requested, predicted satellite clocks, orbits, and ionospheric maps must be used, resulting in a position solution with a much larger error.

The newly developed RT SF-PPP software at Delft University of Technology is based on the in-house SF-PPP software, which uses undifferenced single-frequency pseudorange code and carrier phase observations. The position solution is calculated on an epoch by epoch basis, i.e., truly kinematic. The RT SF-PPP software uses several public GPSrelated products and models to account for the various error sources. These error sources can be split up into three main categories: satellite and propagation effects, site displacements effects, and other algorithm elements. An extensive description of all these effects is given by Kouba (2009). The implementation of these effects in the RT SF-PPP software is described in van Bree et al. (2009).

Instead of using predicted ultra rapid products from IGS (Kouba 2009; Dow et al. 2005), one can use real-time RETICLE products from GSOC/DLR (Hauschild and Montenbruck 2008). These products have been compared in van Bree et al. (2009). In our present work, we make use of RETICLE real-time satellite clocks and orbits.
The RETICLE system computes clock corrections for the entire GPS constellation in real-time, currently based on a world-wide network of 37 reference stations. The estimated clocks are provided with a sampling interval of $10 \mathrm{~s}$ and a latency of $5 \mathrm{~s}$. A more detailed description of the data-processing setup and precise orbit determination results with RETICLE products are contained in Hauschild and Montenbruck (2008). The technical aspects of using RETICLE products in the RT SF-PPP software are described in van Bree et al. (2009). In the present research, the predicted global ionospheric maps (GIM) and predicted DCB from the Center for Orbit Determination (CODE) in Bern are used in order to make possible real-time SF-PPP.

\section{Test setup}

In van Bree et al. (2009), a JPS Legacy receiver was used, and static positioning results with L1 frequency observations were analyzed. In the present work, the high-end receiver Trimble 4700 is chosen whose noise characteristics are well known (Bona 2000a, b). This receiver delivers white noise code and phase observables on L1, sampled at $1 \mathrm{~Hz}$ (Bona 2000b). The receiver, referred to as "DELF", is located at the permanent TU Delft GNSS observatory platform on top of the Netherlands Metrology Institute (NMi) building in Delft. The position of this location is known at the millimeter level in the ITRF2005-ECEF reference frame.

The properties and locations of the selected receivers in the IGS network are listed in Table 1. The known "truth" positions are obtained from the EUREF permanent GNSS network (http://www.epncb.oma.be) and the JPL-website (http://sideshow.jpl.nasa.gov).

The case study single-frequency receiver, a Septentrio AsteRx1, was positioned on the roof of an apartment building about $3 \mathrm{~km}$ away from the observatory in Delft, and the position coordinates have been determined with centimeter-level accuracy.

Between January 30 and April 22 of 2010, data were collected using the DELF receiver and the IGS receivers. Data were actually recorded at a $1 \mathrm{~s}$ interval, but were decimated for archiving purposes to a $30 \mathrm{~s}$ interval, and also processed in daily batches with that interval. The data are as raw and unsmoothed as possible.

For the case study, data were recorded during a period of 9 days in July 2010 with both the high-end DELF receiver, as well as the dedicated case study receiver. Both receivers used a $1 \mathrm{~s}$ interval, but data were decimated and processed at a $30 \mathrm{~s}$ interval (Table 2). It has been verified that truly single-frequency data were used from a dual frequency receiver, and also that for instance, some form of advanced 
Table 1 Receivers, antennas, recorded sample interval, and location in latitude and longitude

\begin{tabular}{|c|c|c|c|c|c|}
\hline Location & Receiver & Antenna & $\begin{array}{l}\text { Sample } \\
\text { interval [s] }\end{array}$ & Latitude $\left[{ }^{\circ}\right]$ & Longitude $\left[{ }^{\circ}\right]$ \\
\hline Delft (DELF) (The Netherlands) & Trimble 4700 (CORS) & TRM29659.00 & 30 & $51^{\circ} 59^{\prime} 09^{\prime \prime}$ & $+4^{\circ} 23^{\prime} 15^{\prime \prime}$ \\
\hline Gebze (Turkey) & Trimble 4700 & TRM29659.00 & 30 & $40^{\circ} 47^{\prime} 12^{\prime \prime}$ & $+29^{\circ} 27^{\prime} 02^{\prime \prime}$ \\
\hline Zimmerwald (Switzerland) & Trimble NetRS & TRM29659.00 & 30 & $46^{\circ} 52^{\prime} 37^{\prime \prime}$ & $+7^{\circ} 27^{\prime} 55^{\prime \prime}$ \\
\hline Blythe (USA) & Trimble NetRS & ASH701945B_M & 30 & $33^{\circ} 36^{\prime} 36^{\prime \prime}$ & $-114^{\circ} 42^{\prime} 36^{\prime \prime}$ \\
\hline Riobamba (Ecuador) & Trimble NetRS & TRM41249.00 & 30 & $-1^{\circ} 39^{\prime} 02^{\prime \prime}$ & $-78^{\circ} 39^{\prime} 03^{\prime \prime}$ \\
\hline Koganei (Japan) & Trimble NetRS & ASH701945C_M & 30 & $35^{\circ} 42^{\prime} 37^{\prime \prime}$ & $139^{\circ} 29^{\prime} 17^{\prime \prime}$ \\
\hline Whangaparaoa Peninsula (New Zealand) & Trimble NetRS & TRM41249.00 & 30 & $-36^{\circ} 36^{\prime} 10^{\prime \prime}$ & $174^{\circ} 50^{\prime} 03^{\prime \prime}$ \\
\hline Delft (The Netherlands) & Septentrio AsteRx1 & AeroAntenna AT575-70 & 1 & $52^{\circ} 00^{\prime} 11^{\prime \prime}$ & $+4^{\circ} 21^{\prime} 33^{\prime \prime}$ \\
\hline
\end{tabular}

For more information, see the websites of the IGS Tracking network and the permanent TU Delft GNSS observatory. The last row lists the receiver used for the case study. Only the $\mathrm{C} 1$ pseudorange and L1 carrier phase observables at L1 frequency are used from these receivers

pseudorange code smoothing were not applied to the data from the receivers used in this research.

In Schaer (2008), it is described how to handle the DCB with different types of receivers. A statement on this issue regarding the type of the DELF receiver is given in IGS Mail 3887 (see IGS Electronic Mail, 17 May, Message Number 3887, S. Schaer, Trimble 4700, 2002) and in Dow et al. (2005).

As a final note, the datasets were processed after the fact, i.e., post-processed, but "as if" in real-time (re-played), strictly with public GPS related products available at the time of observation.

\section{Test results}

The position accuracy results are presented in terms of three statistics: first, the mean $\hat{\mu}$ of the error (estimated minus truth), secondly, the empirical standard deviation $\hat{\sigma}$ of the error about the mean, and finally, the 95 percentile of the error (about zero), generally referred to as the $95 \%$ error. We will also be able to judge the significance of the results obtained. Therefore, the expected value of the sample mean, $E\{\underline{\mu}\}$, the formal variance of the sample mean, $\sigma_{\hat{\mu}}^{2}$, the expectation value of the variance, $E\left\{\underline{\hat{\sigma}}^{2}\right\}$, and the variance of the sample variance, $\sigma_{\hat{\sigma}^{2}}^{2}$ are calculated.
They are given by

$$
E\{\underline{\hat{\mu}}\}=\mu ; \quad \sigma_{\hat{\mu}}^{2}=\frac{\sigma^{2}}{N}
$$

and

$E\left\{\underline{\hat{\sigma}}^{2}\right\}=\sigma^{2} ; \quad \sigma_{\hat{\sigma}^{2}}^{2}=\frac{2 \sigma^{4}}{N-1}$

with $\mu$ the true but unknown mean, $\sigma$ the true but unknown standard deviation, and $N$ the number of used samples. The precision of the mean is then given by $\sigma_{\hat{\mu}}$.

The precision of the variance can be expressed in the precision of the standard deviation, $\sigma_{\hat{\sigma}}$, using the approximate error propagation law for non-linear functions

$\sigma_{\hat{\sigma}^{2}}=\sqrt{\sigma_{\hat{\sigma}^{2}}^{2}} \approx 2 \sigma_{\hat{\sigma}} \sigma$

The equation for the variance of the sample variance is valid under the assumption that the samples are taken from an elliptically contoured distribution. In Table 3, the precision of mean and standard deviation are calculated for several values of standard deviations, for the minimum and maximum number of samples used in this research. The conclusion is that the precision of the parameters presented in our research is at the millimeter scale, which is better (smaller) than the resolution of the numerical results given in the tables on position accuracy.

Table 2 Datasets used in the research

\begin{tabular}{lllrl}
\hline Receiver & $\begin{array}{l}\text { From date } \\
\text { [dd-mm-yyy] }\end{array}$ & $\begin{array}{l}\text { Until date } \\
\text { [dd-mm-yyyy }\end{array}$ & $\begin{array}{c}\text { \# of days } \\
\text { of samples }\end{array}$ \\
\hline Rx's of Table 1 incl. DELF Trimble 4700 & $30-01-2010$ & $22-04-2010$ & 83 & 239,040 \\
DELF Trimble 4700 Septentrio AsteRx1 & $23-07-2010$ & $31-07-2010$ & 9 & 25,920 \\
\hline
\end{tabular}

Last column gives total number of samples used in analyses. All data were processed at a $30 \mathrm{~s}$ interval with a $5^{\circ}$ elevation cut-off angle 
Table 3 Precision of mean, $\sigma_{\hat{\mu}}$, and precision of standard deviation, $\sigma_{\hat{\sigma}}$, for several values of standard deviation $\sigma$ and number of samples $N$

\begin{tabular}{llll}
\hline$\sigma[\mathrm{m}]$ & Number of samples $N$ & $\sigma_{\hat{\mu}}[\mathrm{mm}]$ & $\sigma_{\hat{\sigma}}[\mathrm{mm}]$ \\
\hline 0.10 & 25,920 & 0.6 & 0.4 \\
0.30 & 25,920 & 1.9 & 1.3 \\
0.50 & 25,920 & 3.1 & 2.2 \\
0.10 & 239,040 & 0.2 & 0.1 \\
0.30 & 239,040 & 0.6 & 0.4 \\
0.50 & 239,040 & 1.0 & 0.7 \\
\hline
\end{tabular}

Case study results

L1 results

The results described in this section are based on the high-end receiver in Delft and the six IGS receivers. The results in Table 4 are given for the North, East, and Up component in terms of mean, standard deviation and $95 \%$ error.

The results in Table 4 have been obtained by taking all position errors of all days together and calculating the statistical properties of the distributions of those errors. An example of the distributions and statistical properties is shown in Fig. 1 for receiver DELF. The relative frequency histograms of the North, East, and Up position errors with L1 measurements are presented with the relative frequency as a percentage, versus the error in meters on the horizontal axis.

As an example, Fig. 2 shows the convergence behavior of the position solution. The magnitude of the position error is given as a function of the time of day, with the processing of the daily batches starting at 00:00 h. These graphs have been created using all 83 days of L1-frequency data of the Delft receiver. Plotted are the 50, 68, and 90 percentiles, respectively, by yellow squares, blue circles, and red triangles. The 68 percentile of the vertical position solution reaches a level of $30 \mathrm{~cm}$ (Table 4) in about $1 \mathrm{~h}$ and $20 \mathrm{~min}$, or 160 epochs. Correspondingly, the horizontal position solution reaches about $20 \mathrm{~cm}$ in $1 \mathrm{~h}$ and $30 \mathrm{~min}$, or 180 epochs. It should be noted that data were processed here only at a $30 \mathrm{~s}$ interval, and that the computed solution is - though the data are from a static receiver-truly kinematic.
The moderate-cost case study receiver (order $1 \mathrm{k} €$ ) is a single-frequency $\mathrm{L} 1$ receiver with a simple 5-cm diameter patch antenna (Fig. 3). The positioning performance is given in Table 5 and compared with the single-frequency performance of the DELF receiver. For both receivers, data were processed over the same period of time (July 23-31, 2010), and the same public GPS-related products were used. Fig. 4 shows the position error distributions and their statistical properties of the case study receiver.

\section{Discussion}

The real-time single-frequency precise point positioning results are discussed in the following sections. First, current results are compared to results from other researchers over the past decade. Then results from the receiver in Delft are compared to results of the selected IGS receivers located around the world. Finally, the results of this receiver are compared to the case study receiver, which gives an indication of the performance when a less costly receiver with a simple patch antenna is used.

L1 results during last decade

In the past few years, research has been done on the performance of single-frequency precise point positioning using L1 measurements (Øvstedal 2002; Le and Tiberius 2007; van Bree et al. 2009). To show how much
Table 4 Mean, standard deviation (SD), and 95\% values of North, East and Up errors for the L1 measurements of receivers in Delft and six IGS receivers

Data are from DOY 30-112 of 2010

a Trimble 4700

b Trimble NetRS

\begin{tabular}{|c|c|c|c|c|c|c|c|c|c|}
\hline \multirow[t]{2}{*}{ Location } & \multicolumn{3}{|c|}{ North [m] } & \multicolumn{3}{|c|}{ East [m] } & \multicolumn{3}{|l|}{$\mathrm{Up}[\mathrm{m}]$} \\
\hline & Mean & SD & $95 \%$ & Mean & SD & $95 \%$ & Mean & SD & $95 \%$ \\
\hline Delft $\mathrm{t}^{\mathrm{a}}$ & -0.01 & 0.17 & 0.33 & 0.02 & 0.14 & 0.29 & -0.15 & 0.29 & 0.64 \\
\hline $\mathrm{Gebze}^{\mathrm{a}}$ & 0.01 & 0.15 & 0.28 & -0.01 & 0.14 & 0.29 & 0.00 & 0.29 & 0.56 \\
\hline Zimmerwald $^{\mathrm{b}}$ & 0.01 & 0.20 & 0.39 & 0.01 & 0.19 & 0.37 & -0.07 & 0.36 & 0.71 \\
\hline Blythe $^{b}$ & 0.05 & 0.15 & 0.29 & -0.08 & 0.16 & 0.35 & -0.27 & 0.31 & 0.74 \\
\hline Riobamba $^{\mathrm{b}}$ & 0.10 & 0.24 & 0.46 & -0.12 & 0.37 & 0.79 & 0.35 & 0.46 & 1.07 \\
\hline Koganei $^{\text {b }}$ & 0.04 & 0.24 & 0.45 & 0.00 & 0.21 & 0.40 & 0.06 & 0.51 & 0.95 \\
\hline Whangap. p. ${ }^{b}$ & 0.02 & 0.16 & 0.30 & 0.03 & 0.17 & 0.34 & 0.30 & 0.38 & 0.91 \\
\hline
\end{tabular}



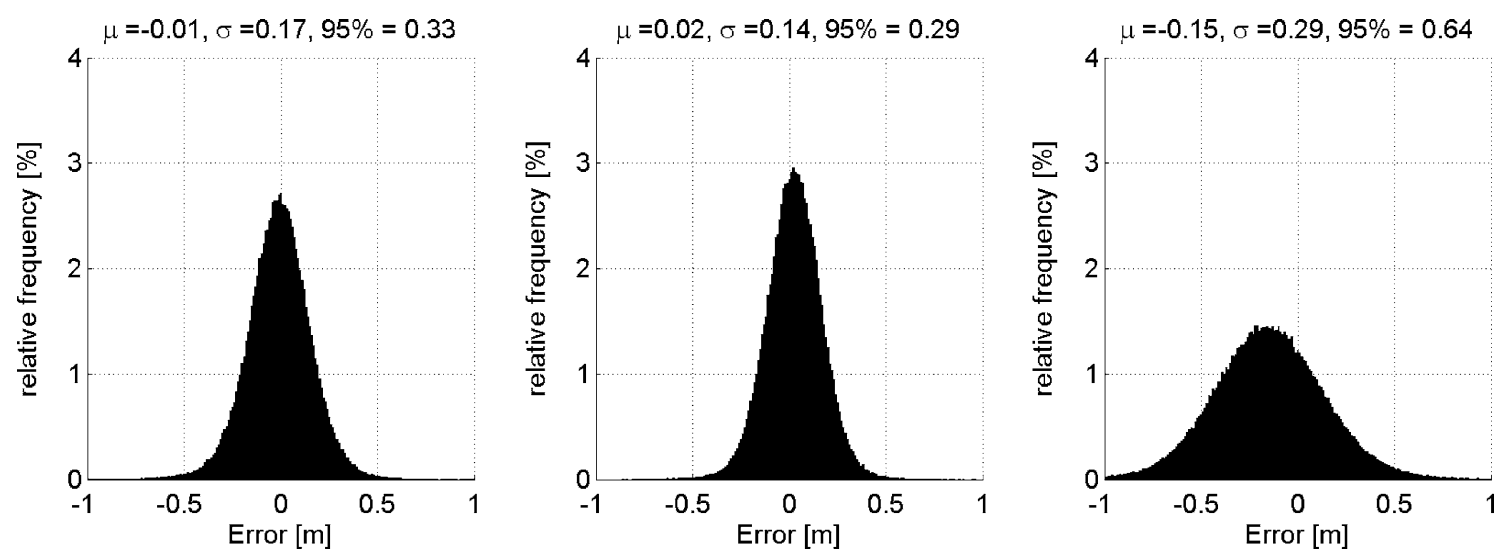

Fig. 1 Distributions of the North (left), East (middle), and Up (right) position errors of DOY 30-112 (2010) on L1 frequency of the receiver in Delft. Statistical properties of the distributions are given above the graphs

Fig. 2 (left) Convergence of horizontal position of the receiver in Delft over DOY 30-112, 2010, in terms of percentiles. (right) Convergence of vertical position of the same receiver
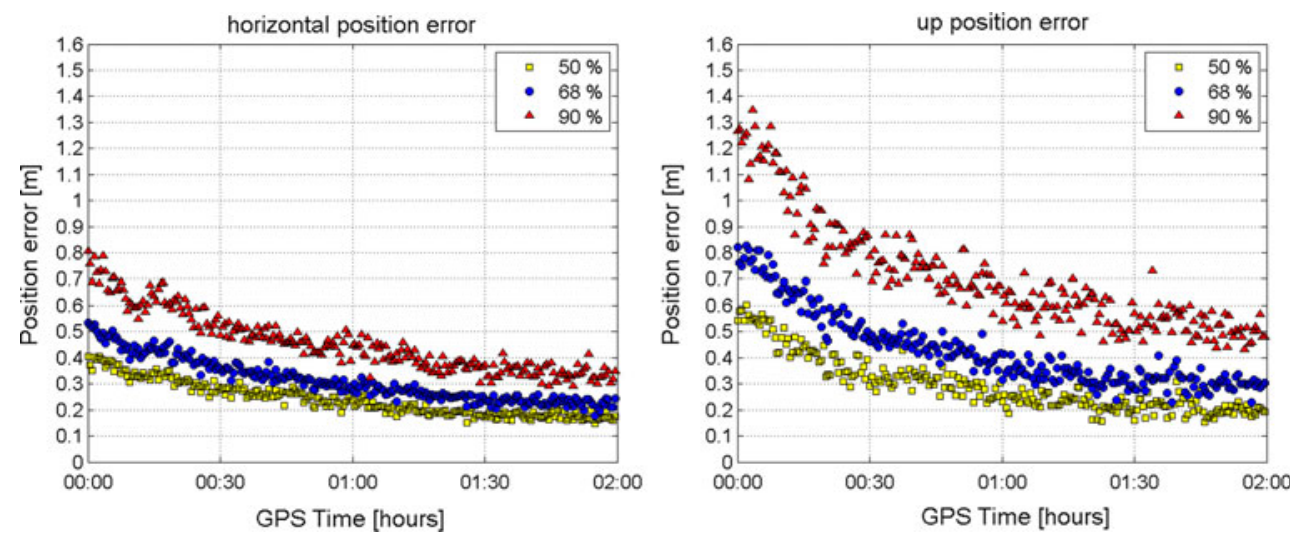

performance has improved over the last decade, an indicative comparison of positioning error statistics is made in Table 6 .

The research by Øvstedal (2002) uses the "corrections" from IGS, which was newly available at the time. The standard deviations reached around $1 \mathrm{~m}, 95 \%$ errors were not given. Le and Tiberius (2007) investigated single-frequency PPP static as well as kinematic performance with

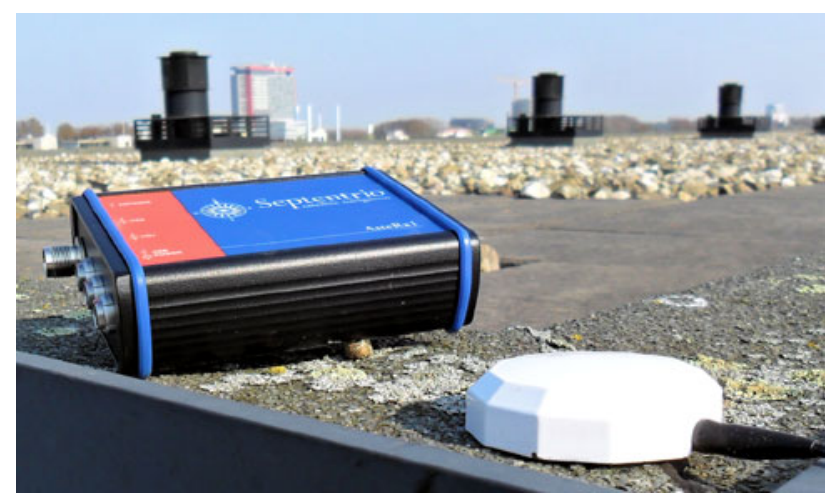

Fig. 3 The Septentrio AsteRx1 single-frequency receiver with the Aero 575-70 patch antenna the use of final products for all corrections that are available weeks after recording. Also the phase adjust algorithm is used (Teunissen 1991). The work by van Bree et al. (2009) examined the potential of the RETICLE products (Hauschild and Montenbruck 2008) in real-time singlefrequency PPP. The real-time 95\% errors were at the same level as obtained with IGS final products (Le and Tiberius 2007). The present work shows that the position accuracy can improve by at least $25 \%$ when using another receiver, i.e., a JPS Legacy in van Bree et al. (2009) versus a Trimble 4700 in the present work. It must be mentioned that the entries in Table 6 are not based on the same data samples, so the comparison shows not only the improvement in SF-PPP algorithms but also the quality of the used products.

\section{Present L1 results}

When a world wide performance analysis of SF-PPP is made, one must take into account two aspects. The type of receiver and the direct environment of its antenna determine the thermal code observation noise and multipath. Next, the impact of the ionosphere on the position accuracy 
Table 5 Mean, standard deviation, and 95\% values of North, East and Up errors for the L1 measurements of the receiver in Delft, and the dedicated case study receiver

\begin{tabular}{|c|c|c|c|c|c|c|c|c|c|}
\hline \multirow[t]{2}{*}{ Receiver } & \multicolumn{3}{|c|}{ North [m] } & \multicolumn{3}{|c|}{ East [m] } & \multicolumn{3}{|c|}{$\mathrm{Up}[\mathrm{m}]$} \\
\hline & Mean & SD & $95 \%$ & Mean & $\mathrm{SD}$ & $95 \%$ & Mean & $\mathrm{SD}$ & $95 \%$ \\
\hline DELF & -0.05 & 0.18 & 0.38 & 0.11 & 0.19 & 0.43 & 0.19 & 0.34 & 0.79 \\
\hline Case study & -0.31 & 0.35 & 0.90 & 0.21 & 0.27 & 0.68 & 0.00 & 0.54 & 1.07 \\
\hline
\end{tabular}

Data are from DOY $204-212$ of 2010
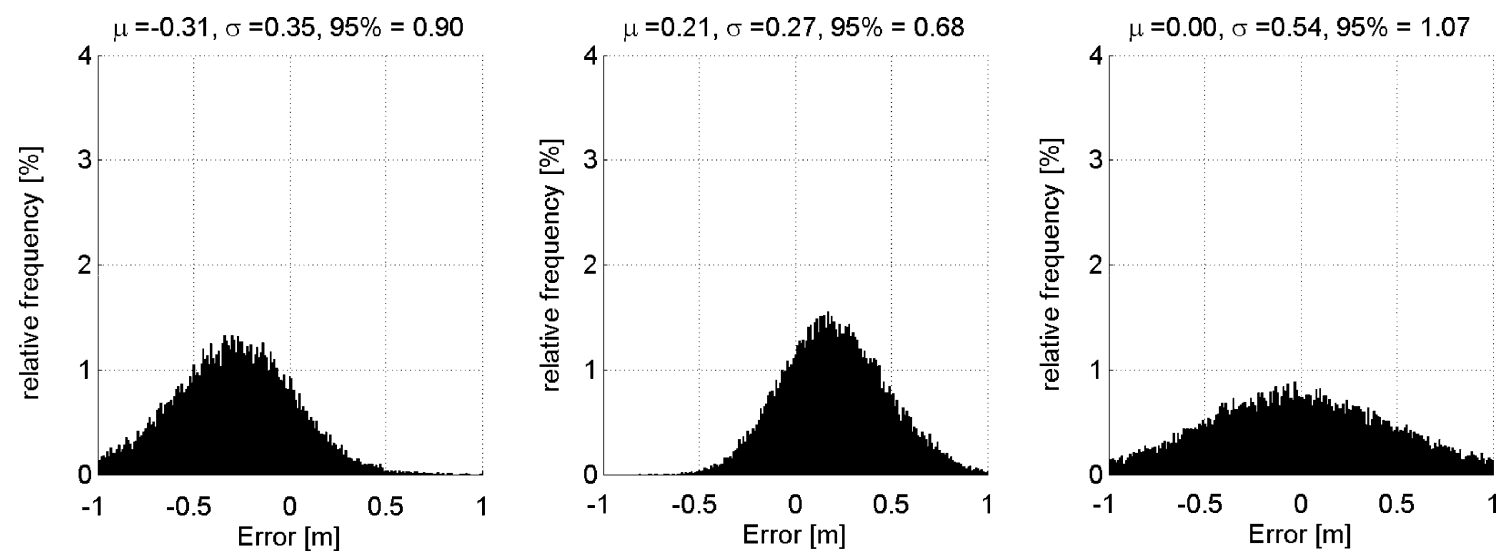

Fig. 4 Distributions of the north (left), east (middle), and up (right) position errors of DOY 204-212 (2010) on L1 frequency of case study receiver in Delft. Statistical properties of the distributions are given above the plots

Table 6 Position error statistics compared with previous research

\begin{tabular}{|c|c|c|c|c|c|c|c|c|}
\hline \multirow[t]{2}{*}{ Reference } & \multicolumn{2}{|c|}{ Horizontal coordinates $[\mathrm{m}]$} & \multicolumn{2}{|c|}{ Vertical coordinate $[\mathrm{m}]$} & \multirow[t]{2}{*}{ Orbits/clocks } & \multirow[t]{2}{*}{ Ionosphere } & \multirow[t]{2}{*}{ DCB } & \multirow[t]{2}{*}{ Real-time } \\
\hline & SD & $95 \%$ & SD & $95 \%$ & & & & \\
\hline Øvstedal 2002 & 0.80 & n.a. & 1.20 & n.a. & $\operatorname{IGS}^{\mathrm{a}}$ & $\mathrm{GIM}^{\mathrm{a}}$ & Nav file & No \\
\hline Le and Tiberius 2007 & n.a. & 0.45 & n.a. & 0.90 & $\mathrm{IGS}^{\mathrm{b}}$ & $\mathrm{GIM}^{\mathrm{b}}$ & $\mathrm{CODE}^{\mathrm{b}}$ & No \\
\hline van Bree et al. 2009 & 0.25 & 0.40 & 0.45 & 0.90 & $\operatorname{Ret}^{\mathrm{c}}$ & $\mathrm{GIM}^{\mathrm{d}}$ & $\mathrm{CODE}^{\mathrm{e}}$ & Yes \\
\hline Present work & 0.15 & 0.30 & 0.30 & 0.65 & $\operatorname{Ret}^{c}$ & $\mathrm{GIM}^{\mathrm{d}}$ & $\mathrm{CODE}^{\mathrm{e}}$ & Yes \\
\hline
\end{tabular}

Given are the standard deviation and $95 \%$ error for the horizontal components and vertical component. The last four columns indicate the types of "corrections" used in SF-PPP for satellite orbits and clocks, ionosphere, DCB's, and real-time operation

IGS International GNSS Service, CODE Center for Orbit Determination in Europe, GIM Global Ionosphere Map, Ret RETICLE, n.a. not available

" Early issues of these "corrections"

${ }^{\mathrm{b}}$ Final products

c RETICLE products

${ }^{\mathrm{d}}$ Predicted products

e 30 day solution ending 5 days prior to file date

is related to the location on earth, and the performance of the RETICLE products, and the quality of the GIM may not be uniform over the earth.

The first two entries of Table 4 (Delft and Gebze in Turkey) give the position results using a Trimble 4700 receiver. The receiver in Delft performs equally well as the receiver in Gebze, aside from a bias in the Up component in Delft. The receivers in Gebze and in Zimmerwald (Switzerland), the latter being a Trimble NetRS receiver, can be expected to undergo the same order of magnitude of ionospheric delays as the one in Delft, therefore the performance should be comparable. Although the 4700 receiver seems to perform slightly better than the NetRS, the three receivers located in Europe show good and 
consistent performance of real-time SF-PPP at mid latitude $\left(\sim 40^{\circ}\right)$.

Notable are the biases in the Up component in Zimmerwald $(-7 \mathrm{~cm})$ and in Delft $(-15 \mathrm{~cm})$. These biases could be caused by small biases present in the predicted GIM from CODE. In the past, biases in the GIM were detected by Orús et al. (2003) and Sekido et al. (2003). The stated GIM accuracy by CODE of 2-8 TECU, equal to $0.32-1.28 \mathrm{~m}$ of zenith range delay at L1 frequency, does not exclude the possibility of small biases in the maps themselves. Another explanation of the small biases could be the presence of multipath, an effect depending strongly on location and the direct surroundings of the antenna of the receiver. Both effects, i.e. GIM biases and multipath, are assumed to be present in the position results, and to investigate this in depth, analysis of SF-PPP results over a period of at least 11 years (one solar cycle) would be necessary. Initial investigations on the results from Delft indicate that on the average, using trend analysis, the bias in the Up component is moving from $-0.25 \mathrm{~m}$ at day 30 , to $-0.05 \mathrm{~m}$ at day 112 , and up to $+0.20 \mathrm{~m}$ at day 212 . The period considered mainly covers spring into the beginning of summer and is therefore pointing in the direction of the ionospheric map bias hypothesis.

The receivers located at lower latitudes (Blythe in USA and Whangaparaoa Peninsula in New Zealand) show horizontal and vertical precision results similar to the Zimmerwald receiver. The bias in the Up direction is larger than for the mid latitude stations, probably caused by larger biases in the GIM maps. The station in Koganei (Japan) shows some degraded precision (larger standard deviations), because it is located closer to the magnetic equator than the other two lower latitude stations. The hypothesis that higher ionospheric activity leads to an increase in standard deviation can also be noticed when the results from Delft are compared between spring (Table 4) and the beginning of summer (Table 5).

The receiver located in Riobamba (Ecuador), which is near to the magnetic equator, shows position results likely influenced by ionospheric disturbances. Compared to the other receivers, both precision and accuracy are degraded, probably by local scintillation effects and/or by poorer coverage of the GIM in that region because of fewer IGS stations. These results give a first indication of real-time SF-PPP performance in the equatorial zone.

The differences in position accuracy between the receivers can be explained, as a first hypothesis, by the influence of the ionosphere, i.e., under equal ionospheric conditions real-time SF-PPP would perform equally well around the globe. This would further indicate good global performance of the RETICLE orbits and clocks.

The position solution convergence given in Fig. 2 indicates that it takes about one and a half hour (180 epochs) to achieve the level of accuracy as the full dataset accuracy, for the Delft receiver (Table 4). The presented convergence time is an example, and further investigations of this aspect are part of future research.

Case study results

The position precision for the horizontal coordinates is about $0.35 \mathrm{~m}$ for the case study receiver, and about $0.20 \mathrm{~m}$ for the high-end receiver (DELF). For the vertical coordinate, the precision values are 0.55 and $0.35 \mathrm{~m}$, respectively. The larger biases in the horizontal coordinates could be caused by multipath in combination with the small patch antenna used and its location on the roof, i.e., a symmetric in the far corner. One can state that with a modestly priced receiver, the 95 percentile of the error in all directions is about $1 \mathrm{~m}$ or less. This implies that with real-time SF-PPP, using real-time RETICLE clocks, it becomes possible, for example, to determine which lane a car is driving on a highway. Thereby next generation car navigation and advanced driver assistance may be enabled without requiring local or regional infrastructure, as is the case with Differential-GPS. PPP also avoids transmission of measurement or correction data from a reference station; instead it relies on transmission of so-called state space information, which presents only a modest data throughput.

\section{Conclusions}

A significant improvement of the position accuracy with real-time single-frequency precise point positioning can be gained when a good high-end receiver is used. The realtime performance in the present work increased significantly compared to earlier work presented in van Bree et al. (2009), changing only the receiver and keeping other parameters and options the same.

The position accuracy achieved here-with a kinematic approach-leads to standard deviations of about 0.15 and $0.30 \mathrm{~m}$ for the horizontal and vertical coordinates, respectively, and with $95 \%$ error values of about $0.30 \mathrm{~m}$ and about $0.65 \mathrm{~m}$. With more than 80 days of data processed, a sound statistical basis is given for these conclusions. The results are compared to those for receivers of similar quality, located around the world, to evaluate RT SF-PPP performance, and compared to a less costly receiver also in Delft, to put positioning performance into perspective.

It is shown that in equal latitude regions, RT SF-PPP performs comparably, indicating a uniform global quality of the RETICLE clocks and orbits. Small biases present in the Up direction at mid latitudes are pointing in the direction of the ionospheric map bias hypothesis. When 
variations between the GIM and the actual ionospheric delay grow larger, especially near the magnetic equator, the standard deviations of the coordinates can increase by more than $50 \%$ and biases up to several decimeters.

With a receiver from the mid-range of the GNSS equipment spectrum, satisfactory position accuracies of 95\% error less than $1 \mathrm{~m}$ can be achieved. The accuracy, produced in real-time and with single-frequency data only in a fully kinematic approach, can have large implications for future development of low-cost, high-precision navigation applications. Recommendations for future work include an analysis of the convergence aspect of the solution and actual kinematic tests.

Acknowledgments Many thanks go to André Hauschild from GSOC/DLR for providing the RETICLE orbit and clock products.

Open Access This article is distributed under the terms of the Creative Commons Attribution Noncommercial License which permits any noncommercial use, distribution, and reproduction in any medium, provided the original author(s) and source are credited.

\section{References}

Bona P (2000a) Accuracy of GPS phase and code observations in practice. Acta Geod Geoph Hung 35(4):433-451

Bona $\mathrm{P}(2000 \mathrm{~b})$ Precision, cross correlation and time correlation of GPS phase and code observations. GPS Solut 4(2):3-13

Dow JM, Neilan RE, Gendt G (2005) The International GPS Service (IGS): celebrating the 10th anniversary and looking to the next decade. Adv Space Res 36(3): 320-326

Gao Y, Zhang Y, Chen K (2006) Development of a real-time singlefrequency Precise Point Positioning system and test results. Proceedings of ION GNSS 2006, Sept. 26-29, Fort Worth, Texas, pp 2297-2303

Hauschild A, Montenbruck O (2008) Real-time clock estimation for precise orbit determination of LEO-satellites. Proceedings of the ION GNSS meeting 2008, Sept 16-19, Savannah, Georgia, USA, pp 581-589

Héroux P, Kouba J (1995) GPS precise point positioning with a difference. Geomatics'95, Ottawa, June 13-15

Kouba J (2009) A guide to using international GPS service (IGS) products. [online publication at IGS website]

Le AQ, Tiberius CCJM (2007) Single-frequency precise point positioning with optimal filtering. GPS Solut 11(1):61-69
Orús R, Hernández-Pajares M, Juan JM, Sanz J, García-Fernández M (2003) Validation of the GPS TEC maps with TOPEX data. Adv Space Res 31(3):621-627

Øvstedal O (2002) Absolute positioning with single frequency GPS receivers. GPS Solut 5(4):33-44

Schaer S (2008) Differential Code Biases (DCB) in GNSS analysis, IGS workshop, Miami Beach, June 2-6

Sekido M, Kondo T, Kawai E (2003) Evaluation of GPS-based ionospheric TEC map by comparing with VLBI data. Radio Sci 38(4): 1069

Teunissen PJG (1991) The GPS phase-adjusted pseudorange. Proceedings of the 2nd international workshop on high precision navigation Stuttgart/Freudenstadt, Germany, pp 115-125

van Bree RJP, Tiberius CCJM, Hauschild A (2009) Real time satellite clocks in single-frequency precise point positioning, IONGNSS-2009, Savannah, Sept 22-25, pp 2400-2414

\section{Author Biographies}

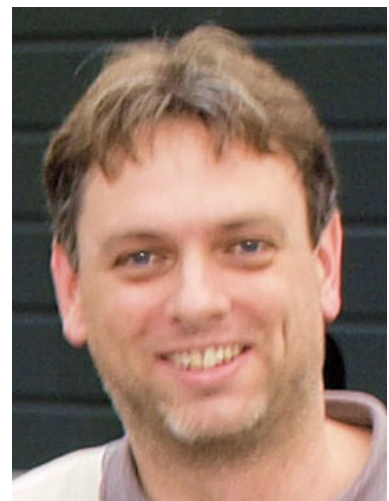

Roel van Bree graduated in astronomy from Leiden University in the Netherlands in 1997. He has worked for ten years at TNO Defense and Security on Synthetic Aperture Radar. Currently, he is working as a research associate at Delft University of Technology on precise point positioning and navigation with GPS and Galileo.

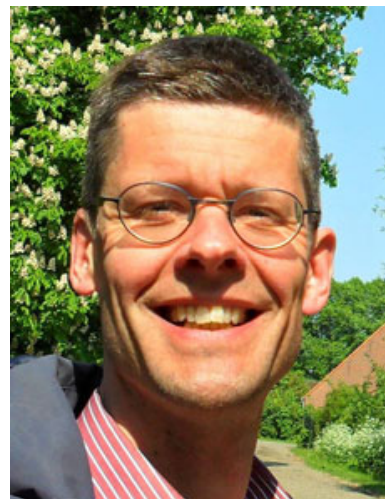

Christian Tiberius is an associate professor at Delft University of Technology. $\mathrm{He}$ is involved in GNSS positioning and navigation research, with emphasis on data quality control, SBAS, and precise point positioning. 